\title{
INSTANTÁNEAS DE AGUSTÍN DE ITURBIDE EN EL SIGLO XIX
}

\author{
SNAPSHOTS OF AGUSTIN DE \\ ITURBIDE IN THE 19TH CENTURY
}

\author{
Guadalupe Cecilia Gómez-Aguado de Alba \\ UNAM-Centro de Investigaciones sobre \\ América Latina y el Caribe \\ gucega@unam.mx
}

\begin{abstract}
Despite his importance in the independence of Mexico, Agustin de Iturbide has been forgotten in commemorations of this historical event. This is a result of the image created of him in the earliest works about his performance in the empire and which was published in biographies soon after his death. In the decades following the consummation of independence. Agustin I was either celebrated as the creator of the Mexican nation or vilified as a man who had betrayed the principles of freedom and independence when crowned as an emperor. This paper analyses several literary sources portraying opposite views of Iturbide.
\end{abstract}

Keywords: Agustin de Iturbide, independence, empire, liberalism, conservatism.

\section{Resumen}

A pesar de la importancia de Agustín de Iturbide en la historia de México, ha sido olvidado en las conmemoraciones de la independencia. A ello ha contribuido la construcción de su imagen en los primeros trabajos sobre su gobierno y la que se plasmó en las biografías que se publicaron casi inmediatamente después de su muerte. Iturbide fue exaltado como el creador de la patria mexicana o denostado como un hombre que había traicionado los principios de libertad e independencia al haberse coronado emperador. En este trabajo se hará un análisis de diversas obras que presentaron imágenes opuestas sobre Iturbide.

Palabras clave: Agustín de Iturbide, independencia, imperio, liberalismo, conservadurismo. 
Si a la lid contra hueste enemiga nos convoca la trompa guerrera, de Iturbide la sacra bandera imexicanos! valientes seguid.

Y a los fieros bridones les sirvan las vencidas hazañas de alfombra; los laureles del triunfo den sombra a la frente del bravo Adalid.

\section{Introducción}

El 27 de septiembre de 1821 se consumó la Independencia de México con la entrada del Ejército Trigarante a la capital del virreinato. En 2021 se conmemoran 200 años de ese acontecimiento que llenó de júbilo a sus contemporáneos y que, en contraste, poco se recuerda hoy en día. En una fecha tan señalada es preciso recordar a uno de sus principales protagonistas, el general Agustín de Iturbide, ideólogo del Plan de Iguala y del proyecto que llevó al nacimiento de México como nación independiente. No obstante, y pese a su indudable importancia como uno de los personajes centrales en los hechos que se conmemoran este año, Iturbide ha sido una figura incómoda para la historia patria. Identificado con el conservadurismo decimonónico y con los proyectos monárquicos, se le ha relegado al rincón de los antihéroes, y sin llegar a ser un villano, tampoco ha alcanzado la estatura de héroe que le correspondería por derecho propio. Si bien la historiografía se ha ocupado de su figura y se le han dedicado múltiples obras, su imagen en la historia es ambigua y pesa más su fallido gobierno imperial que el logro de haber unido a los diversos grupos que combatían en contra de la corona española para conseguir, después de una década de lucha, la anhelada independencia.

Sobre la historiografía dedicada a Iturbide, Joaquín E. Espinosa Aguirre (2020) lleva a cabo una revisión detallada desde diversos puntos de vista: historiografía contem-

1 VII estrofa del Himno Nacional Mexicano, dedicada a Agustín de Iturbide y modificada en 1910 a instancias de Porfirio Parra. Entonces se sustituyó la frase "de Iturbide la sacra bandera" por "de la Patria la sacra bandera". Finalmente, en 1943 la estrofa fue eliminada de la versión oficial del himno. poránea, biografías, trabajos especializados y compilaciones documentales. En cuanto a las biografías, destaca la de William Spence Robertson (2012), considerada la más completa hasta la fecha (Ávila, 2008: 31), cuya edición original en inglés fue publicada en 1952 y no había sido traducida sino hasta hace unos cuantos años; por su parte, Jaime del Arenal Fenochio (2002a) escribió un trabajo de divulgación que complementó más adelante con una obra que analiza los antecedentes de la consumación y las propuestas de gobierno de Iturbide (Del Arenal, 2002b). Esta misma obra fue reeditada con nuevas reflexiones (Del Arenal, 2010). Timothy E. Anna (1991), Alfredo Ávila (2008) y Rafael Estrada Michel (2021) analizan diversos aspectos del gobierno y del imaginario iturbidista. Jaime Cuadriello (2010) hace un estudio de la imagen de Iturbide desde la perspectiva del arte. Verónica Zárate Toscano (1994) analiza el periplo de los restos del consumador de la Independencia, su destino entre los héroes insurgentes, las primeras noticias sobre él en los relatos de historia patria a lo largo del siglo XIX y el debate del que fue objeto su figura hasta el primer centenario de la consumación de la gesta independentista. En 1971 Alfonso Junco publicó un estudio sobre Iturbide en la mirada de insurgentes y liberales, que formó parte de una serie de obras de corte conservador que buscaban mantener vivo el culto a Iturbide, publicadas por la editorial Jus (Frasquet, 2007: 39).

En el siglo XIX, por otra parte, desde fechas muy tempranas vieron la luz varias obras de historia de México en las que, como es lógico, la lucha por la independencia y por lo tanto la figura de Iturbide tuvieron una importancia fundamental. Entre ellas destacan Vicente Rocafuerte (1822), Carlos María de Bustamante (1821-1827), Lorenzo de Zavala (1831-1832), Lucas Alamán (1849-1852), Julio Zárate y Juan de Dios Arias (1987) y Niceto de Zamacois (1888). También se escribieron trabajos dedicados específicamente a diversos aspectos de la vida y muerte de Agustín de Iturbide, desde la temprana narración de su efímero gobier- 
no y su trágico final, hasta las que a fines del régimen porfiriano buscaron rescatarlo como protagonista de la lucha por la emancipación de la patria mexicana. Entre ellas podemos mencionar a Manuel Payno, que hizo un bosquejo biográfico sobre Iturbide y Manuel Mier y Terán y afirmó que ambos personajes habían recorrido una "senda de gloria" y encontraron un destino fatal que los unió en la muerte. El anhelo de Payno era que ya no hubiera escenas tan atroces y sangrientas como la ejecución de Iturbide y el suicidio de Mier y Terán (Payno, 1843: 2). José Ramón Pacheco (1849) narró con detalle las honras fúnebres que se hicieron al consumador de la Independencia en 1838 e incluyó en su obra varios documentos que contienen su despedida de México al salir al exilio y sus últimas palabras antes del fusilamiento. José María Díaz Noriega hizo una reflexión sobre la exhumación de los restos de Iturbide en un momento en que a su decir la existencia política de México estaba en peligro "por culpa de los enemigos de las preciosas garantías que se proclamaron en Iguala" (1860: 21). José Joaquín Pesado (1872) escribió una biografía para el Diccionario Universal de Historia y Geografía en 1853 que se reeditó en 1872. Ramón Valle (1885) dedicó a Simón Bolívar y a Agustín de Iturbide un "Canto secular" en el que exaltó la obra de Iguala y equiparó al consumador con George Washington y el propio Bolívar. Antonio de P. Moreno (1896) publicó un drama histórico en verso sobre la vida y muerte de Iturbide. Vicente Riva Palacio, cuyo texto sobre don Agustín se publicó en una edición conmemorativa de Victoriano Agüeros, recreó la consumación de la independencia y el fin del caudillo y reflexionó sobre la ingratitud de la nación mexicana, que al matar a quien logró la independencia había atentado contra la vida de "su padre" (1910: 317).

En cuanto a la construcción de la imagen de Iturbide en el siglo XIX, en el mundo occidental esa centuria fue una época de regreso a los orígenes, al tiempo primordial, y para justificar la aparición de las naciones, se apeló a un tiempo ido en el cual esta- ban las raíces de la legitimidad de la nación misma. Así, muchos de los personajes que lucharon por construirla, o que dieron su vida para formar una patria, se convirtieron en héroes míticos. $Y$, al mismo tiempo, fue necesario dotar a las nuevas entidades nacionales, como fue el caso de México después de su Independencia, de un pasado esplendoroso del cual enorgullecerse y de una patria preexistente que fue liberada por el sacrificio que hicieron los grandes hombres para recuperar la libertad. De modo que la tarea de legitimar a la nueva entidad política y la lenta y dolorosa consolidación del Estado-nación fueron procesos que se apoyaron en el rescate de los protagonistas del pasado para dotar de elementos de identidad a los habitantes de la patria mexicana (Gómez-Aguado, 2012). Los estados nacionales debieron crearse e "inventar" una memoria histórica que legitimara su pasado (Pérez Vejo, 2010). Agustín de Iturbide fue uno de los protagonistas, para bien o para mal, del panteón de héroes nacionales. En este trabajo se hará un análisis de la construcción de la imagen de Iturbide en la época decimonónica, con el fin de acercarnos a la imagen histórica de un personaje que ha sido denostado o las más de las veces ignorado en las conmemoraciones de la Independencia de México.

\section{Iturbide y el relato histórico de su desventura}

¿Cómo se construyó la imagen histórica de Agustín de Iturbide? ¿En qué momento su figura se convirtió en argumento a favor o en contra de determinado proyecto político? Como afirma Rafael Estrada Sámano, muchos investigadores se han acercado con interés al personaje y su infausta muerte ha sido objeto de conmiseración, pero pocos han escapado "a la influencia de un criterio ideológico determinado para analizar y evaluar su trágico destino, así como la conducta del prócer que con su Plan de Iguala hizo posible la consumación de la Independencia" (Robertson, 2012). No obstante, en la segunda década del siglo XXI, 
de acuerdo con Rafael Estrada Michel (2021: 313), las diatribas de las que Iturbide ha sido objeto desde el oficialismo y la escasez de críticas serias paradójicamente han permitido un acercamiento más objetivo a su figura, a diferencia de lo que ha sucedido con otros personajes calificados como héroes por la historia de bronce. En ese sentido, el proyecto independentista del libertador ha emergido en los últimos estudios como un plan que retomó aspectos de la primera insurgencia, pero también buscó la moderación y la unidad de todos los habitantes de la América Septentrional (Estrada, 2021: 314). El Plan de Iguala puede calificarse, en palabras de Guadalupe Jiménez Codinach, como una "obra maestra de política conciliatoria" (Estrada, 2021: 315). ${ }^{2}$

Pero en los 200 años transcurridos entre 1821 y 2021 no siempre se ha entendido el objetivo de Iturbide al consumar la independencia y si bien en este bicentenario parece que su figura se estudia con mayor ponderación, esto no ha sido lo más común, sobre todo si nos acercamos a la historiografía de los contemporáneos de Iturbide y de quienes lo utilizaron como bandera política de grupos antagónicos.

De hecho, con motivo del bicentenario del inicio del movimiento insurgente se publicaron variadas reflexiones sobre estos hechos, y se habló de Iturbide, junto con Porfirio Díaz y Antonio López de Santa Anna, como los antihéroes por excelencia, llamados irónicamente por Mauricio Tenorio Trillo "los tres santos traidores del siglo XIX mexicano" (2009: 142).

De acuerdo con Jaime Cuadriello, la personalidad de Agustín de Iturbide "permanece confinada al depósito de la desmemoria o la invisibilidad colectiva" (2010: 145), ya que en 2010 no había merecido una biografía ni había sido objeto de mayores reivindicaciones. Por su parte, Anna afirmó que

2 De acuerdo con Jiménez Codinach, citada por Estrada Michel, el Plan de Iguala "recoge preocupaciones de los criollos de 1808, algo de las banderas insurgentes de Hidalgo, Rayón y Morelos, fórmulas liberales y constitucionales de próceres como Mina, a la vez que tranquiliza a grupos conservadores que temen medidas radicales parecidas a las tomadas por los liberales españoles del Trienio Constitucional” (2021: 315). por "usurpador y tirano, está consignado a un destino peor que el considerarlo como un villano: se ha convertido tal vez en la no-persona más importante de la historia mexicana" (Anna, 1991; citado en Cuadriello, 2010: 145).

Al respecto, Tenorio Trillo ironiza al destacar que 1820 vio nacer al héroe "más popular que la América del Septentrión había conocido hasta entonces. [Sin embargo] para 1824 era el primer traidor absoluto de la historia nacional, uno de esos villanos indispensables para las historias patrias" (Tenorio, 2009: 135). De ahí que se haya convertido en un personaje difícil para la historia oficial del siglo XX. Su expulsión del panteón de héroes liberales por su rechazo al republicanismo tampoco lo hizo merecedor de estar al lado de los acusados de traición como Santa Anna, ya que a pesar de que se ha minimizado su actuación en la insurgencia, jugó un papel fundamental en el nacimiento de la nación mexicana (Ávila, 2010: 21).

Para analizar cómo se van creando las contradicciones en la imagen de Iturbide, es preciso echar un vistazo a la construcción de la historia patria en el siglo XIX. Entre los primeros relatos y la obra cumbre de la historiografía decimonónica, México a través de los siglos, pasaron más de cinco décadas plagadas de enfrentamientos civiles, invasiones extranjeras y problemas económicos. De esos años perdura el recuerdo de la guerra contra Estados Unidos y la dolorosa pérdida de más de la mitad del territorio nacional, así como de las recurrentes luchas armadas, especialmente la guerra de Reforma y la intervención francesa. Los ensayos de organización política que incluyeron monarquía, república federal, república central y dictadura fueron escenario de enfrentamientos constantes.

De ahí que no se haya consolidado un relato que consagrara los hechos y personajes principales de nuestro pasado sino hasta el llamado "triunfo de la república", cuando la historia decimonónica puso fin al debate entre dos visiones de ese tiempo ido: la historia liberal y la historia conservadora. 
En años previos hubo muchas manifestaciones de esa disputa por el protagonismo del movimiento insurgente, por ejemplo, el debate sobre quién merecía ser considerado el libertador de México, si Miguel Hidalgo o Agustín de Iturbide.

Las discusiones al respecto se sustentaron en obras como el Cuadro histórico de Bustamante; el Ensayo histórico de las revoluciones de México de Zavala, así como en la Historia de Méjico de Alamán, por mencionar algunos ejemplos.

A partir de 1867, fecha que marca la caída del segundo Imperio, la historia liberal fue predominante, y se adoptó un discurso patriótico que quedó plasmado en la gran obra histórica del porfiriato: México a través de los siglos, cuyos cinco tomos tuvieron la virtud de formar una historia abarcadora que integró pasados que se habían considerado irreconciliables: la antigüedad prehispánica con el virreinato y a ambos con la guerra de Independencia, los primeros años de la república y la Reforma (Florescano, 2002: 353).

Por su parte, la visión conservadora fue obra de Niceto de Zamacois, quien en los 18 tomos de su Historia de Méjico buscó la unión de los mexicanos mediante el análisis de su pasado, pero no solamente desde el punto de vista de los conflictos bélicos y los enfrentamientos ideológicos, sino también desde la perspectiva del devenir histórico como un proceso lineal ascendente y progresivo, guiado por una voluntad suprema que había favorecido a la patria mexicana con el influjo de la religión católica, punto cardinal de su discurso.

Para él, vizcaíno de origen y mexicano por adopción, sólo mediante el conocimiento del pasado y el respeto a la religión se lograría la reconciliación de los habitantes del país y por ende la anhelada paz (Torre, 2011: 560-562). Para conocer cómo se llegó a la síntesis histórica de las obras antes mencionadas, haremos un repaso de las imágenes del libertador a lo largo del siglo XIX.

\section{Iturbide en los primeros escritos sobre su gobierno}

\author{
¿Conque ya no soy rey? ¿Ya no soy nada? \\ ¿En un momento se acabó mi imperio? \\ ¿Ya desaparecieron mis amigos \\ cual veletas que mueve el fácil viento? \\ JOAQUÍN FERNÁNDEZ DE LIZARDI \\ El unipersonal de Don Agustín de Iturbide, \\ emperador que fue de México
}

En 1823 José Joaquín Fernández de Lizardi publicó un monólogo de 503 versos en el que imaginó cuáles pudieron ser las reflexiones de Agustín I después de su abdicación (Fernández, 2016). Ahí denunciaba su inexperiencia, la traición de los amigos, la gloria vivida al consumar la independencia y el ridículo de haber aceptado un trono que era hijo de la adulación y del absurdo. En los versos del Pensador mexicano, el emperador aparece como un hombre engañado por las intrigas y lisonjas de quienes lo rodeaban: "iOh, ministros perversos! iOh malvados / amigos intrigantes, lisonjeros / que me ocultabais la verdad! Yo, beodo / con vuestra sumisión y acatamiento / engañado pensé que me estimábais / por mi persona, no por el bien vuestro" (Fernández, 2016). La coronación, las fiestas, los arcos de triunfo y todo el boato que acompañó a la efímera corte imperial fue motivo de ironía en las letras de Lizardi, que se imagina a Iturbide, una vez despierto del sueño imperial

triste, solo, abatido, sin amigos, / de todos infamado, hecho objeto / del odio y la venganza, sin asilo, / sin recurso ninguno y a un destierro / por favor de la patria confinado / y escoltado de tropa... iSanto cielo!, / ¿y aún puedo yo vivir? ¿Aún el ambiente / alcanzo a respirar? $\bigcirc$ estoy durmiendo / o debo ser de mármol insensible, / pues con tanto dolor morir no puedo (Fernández, 2016).

Haber aceptado el trono que no supo sostener con prudencia y valor fue, desde la perspectiva de Lizardi, el mayor pecado cometido por Iturbide, que había logrado liberar a la patria, pero no había podido 
sustraerse a las mieles del poder. Contrito, avergonzado, el emperador pedía perdón a los mexicanos por sus errores y comprendía que las coronas y los cetros no eran lo que buscaba el pueblo, sino la libertad que no era la del trono (Fernández, 2016).

La imagen que plasma Fernández de Lizardi contrasta con la que legó a la posteridad Vicente Rocafuerte, uno de los malquerientes de Iturbide, cuyo texto contribuyó a crear una visión profundamente negativa sobre nuestro personaje. La obra del ecuatoriano, publicada de manera anónima en 1822, es una defensa del liberalismo y una acusación abierta en contra del proyecto monárquico encabezado por Iturbide (Rocafuerte, 1822). ${ }^{3}$ El personaje, un partidario del republicanismo, estaba convencido de que cualquier sistema monárquico, aunque se tratara de una monarquía constitucional, desembocaría en una tiranía. Por ello, se reunió con integrantes de la facción republicana en México, entre otros los padres Mier y Miguel Ramos Arizpe, que temían que Estados Unidos reconociera al gobierno de Iturbide. Sus intenciones eran derrocar al emperador, y para ello le confiaron a Rocafuerte la encomienda de viajar al vecino país para evitar el reconocimiento diplomático, organizar una invasión y publicar un ataque documentado contra el emperador. En agosto de aquel año, Rocafuerte redactó su libelo en La Habana, firmado por "un verdadero americano" y supuestamente editado en Filadelfia (Aguilar, 2012: 79-80). En esa época tan temprana, de la mano de los partidarios del sistema republicano, comenzó a gestarse la oposición entre monarquía y república y a pesar de que las monarquías constitucionales tenían un origen liberal, fueron catalogadas como contrarias al liberalismo e indefectiblemente ligadas con el absolutismo y la tiranía (Aguilar, 2012: 69-70).

Vicente Rocafuerte nos legó una imagen totalmente negativa de Agustín de Iturbide. Lo acusó de formar parte de una conjura en contra de la Constitución de Cádiz y a fa-

3 El trabajo de Vicente Rocafuerte, firmado por "Un verdadero americano", tiene un pie de imprenta falso que en realidad es un anagrama de sus apellidos: "Teracrouef y Nasroajeb" por "Rocafuerte y Bejarano". vor del absolutismo, conocida popularmente como conspiración de La Profesa. Afirmó que los conjurados eligieron a un americano "capaz de vender a sus compatriotas" y entre los que "sacrificaban su patria a su ambición y se habían distinguido por su servilismo" encontraron a Iturbide. De acuerdo con Rocafuerte, el originario de Valladolid había destacado desde jovencito por sus malas inclinaciones, por tener un corazón "cruel y duro", por "vicioso y desaplicado" y por sus malignas travesuras que casi habían causado la muerte a un condiscípulo al que aventó por las escaleras; su crueldad se notaba en la forma en que torturaba a las aves de corral (Rocafuerte, 1822: 7). En cuanto pudo se alistó en el ejército realista, con el único fin de "tener grados, dinero y hacer fortuna (...) aun convirtiéndose en verdugo y asesino de sus mismos paisanos y hermanos". Persiguió "atrozmente a los beneméritos de las Américas, a los dignos héroes de la independencia”, y ejerció notorios actos de crueldad contra los insurgentes, incluidos niños y mujeres (Rocafuerte, 1822: 11-16). Y también era codicioso, ya que sometió a las poblaciones del Bajío a pagos extraordinarios, los despojó de sus posesiones sin miramientos ni consideraciones de ninguna clase y los obligó a comprar las mercancías que él mismo vendía a precios más altos que los del mercado (Rocafuerte, 1822: 17-20). Por si esto fuera poco, el ecuatoriano también esparció un rumor que a la postre se convertiría en motivo de chismes y leyendas, ya que afirmó que Iturbide tuvo amoríos con "una señora principal de México, cuya reputación de preciosa rubia, de seductora hermosura, llena de gracias, de hechizos y de talento, y tan dotada de un vivo ingenio para toda intriga y travesura, que su vida hará época en la crónica escandalosa del Anáhuac" (Rocafuerte, 1822: 21). ${ }^{4}$ Según esta versión, la bajeza de Iturbide llegó a tanto, que fingió una carta escrita por su esposa a un supuesto amante y con ese

4 Esta rubia señora es nada menos que la célebre María Ignacia Rodríguez de Velasco, mejor conocida como la Güera Rodríguez. La versión de los amoríos con Iturbide ha sido descartada por Silvia Marina Arrom (2020) 
pretexto pidió el divorcio y encerró a su mujer en el convento de San Juan de la Penitencia (Rocafuerte, 1822: 21-22).

Al analizar los hechos que llevaron a la consumación de la Independencia, Rocafuerte aseguró que a Iturbide sólo lo movía la ambición y que sus aparentes virtudes en realidad eran movidas por el interés. Nunca ejerció "la generosidad, la conmiseración, ni otra alguna virtud laudable, sino por miras particulares, ya de seducir a alguno para que se entregara o denunciara a los insurgentes, ya para que le descubrieran sus proyectos, y ya para que le sirvieran de emisarios de sus correrías. En una palabra, [era] un hombre connaturalizado con el crimen, con la hipocresía, con la bajeza, con la maldad y con la intriga" (Rocafuerte, 1822: 81). Contrario a las afirmaciones de don Agustín sobre el amor que los mexicanos le profesaban, Rocafuerte afirmó que después de la consumación "el odio a Iturbide estaba tan reconcentrado, que muchos decían que preferían la más tiránica esclavitud a la libertad venida por sus manos" (Rocafuerte, 1822: 84). La coronación de Iturbide después de una elección ilegítima, porque no estaban la mayoría de los diputados del Congreso, mereció toda clase de críticas por parte de Rocafuerte, que lo presentó como un tirano sostenido por las bayonetas (Rocafuerte, 1822: 99). Sostuvo que el gobierno era ilegítimo y su titular un usurpador

sanguinario, ambicioso, hipócrita, soberbio, falso, verdugo de sus amigos, perjuro, traidor a todo partido, connaturalizado con la intriga, con la bajeza, con el robo y la maldad [...] ignorante y fanático, aún no sabe lo que es patria ni religión; entregado al juego y a las mujeres cuando no está empleado en alguna maldad, solo se complace en el vicio [...] He aquí mexicanos, el verdadero retrato de vuestro emperador (Rocafuerte, 1822: 247-248).

El retrato pintado por Rocafuerte carece de matices y presenta el peor rostro de Agustín de Iturbide. De acuerdo con sus tendencias republicanas y sus claros intereses antimonárquicos, quiso convencer a sus lectores de que un hombre capaz de tales actos de crueldad, ambicioso y traidor, no merecía ocupar el trono de México. Además, hombre poco paciente con las faltas ajenas, era hipercrítico y poco caritativo, a decir de Jaime E. Rodríguez (1997: 175). Y lo que es más desafortunado en este retrato tan negro es que muchas de las cosas que escribió sobre Iturbide se siguen repitiendo hoy en día, desde la conspiración de La Profesa hasta los amoríos con la Güera Rodríguez. A partir del panfleto de Rocafuerte muchas de sus aseveraciones fueron retomadas por los partidarios del republicanismo para denostar a Iturbide y su proyecto independentista (Rodríguez, 1997: 177). Se puede decir que ese es el origen de la disputa que fue creciendo a lo largo de la centuria y que identificó a Iturbide con la monarquía y el despotismo mientras el movimiento iniciado por Hidalgo se convertía poco a poco en la bandera del liberalismo.

\section{Después de la muerte del libertador}

\author{
Muero por haber venido a ayudaros, \\ y muero gustoso porque muero \\ entre vosotros; \\ muero con honor, no como traidor: \\ no quedará a mis hijos y su posteridad \\ esta mancha; \\ no soy traidor, no. \\ Agustín de ITURBIDE
}

Los textos antes comentados se escribieron en vida de Iturbide, pero con su muerte acaecida en Padilla el 19 de julio de 1824 por un decreto expedido por el Congreso el 28 de abril de ese mismo año, su figura cobró una nueva dimensión. Así, en 1825 se publicó un texto anónimo sobre su trágico final en el que se describió su fusilamiento y el valor mostrado por Iturbide en sus horas postreras. El autor del impreso lamentaba la muerte del "memorable libertador de la América septentrional”, cuya patria lo lloraba en silencio. Sus últimas palabras fueron incluidas en el documento: 
Mexicanos: en el acto mismo de mi muerte, os recomiendo el amor a la patria y observancia de nuestra santa religión, ella es quien os ha de conducir a la gloria [...] Guardad subordinación y prestad obediencia a vuestros jefes, que haciendo lo que ellos os mandan es cumplir con Dios; no digo esto lleno de vanidad porque estoy muy lejos de tenerla (Anónimo, 1825: 14).

La muerte del libertador moderó los severos juicios que se habían hecho sobre su persona con motivo de su ascenso al trono y sus medidas autoritarias contra el Congreso, aunque no borró los agravios de quienes fueron perseguidos y encarcelados por el malogrado emperador. Tal fue el caso de Carlos María de Bustamante, férreo opositor a Iturbide en los tiempos de su gobierno, conspirador junto con Mier y Rocafuerte, pero que a pesar de ello, en su obra histórica escrita entre 1821 y 1827 trató de presentar una imagen ponderada del "joven caudillo". Mencionó las aclamaciones y la popularidad de que gozó el vallisoletano en los felices días de su entrada triunfal a la capital del reino. Iturbide

caminaba erguido y con paso firme por el sendero de la gloria, que recorrió en el corto espacio de siete meses, constantemente protegido y mimado de la fortuna; que en su ruta holló los fragmentos de las cadenas que rompió al leve impulso de sus brazos, y a cuyo golpe separó al mundo antiguo del nuevo [...]. Iturbide dio ser político a la patria, la colocó en el catálogo de las naciones libres, independientes y soberanas (Bustamante, 1845: 336).

Pero el reverso de la moneda presentó a ese mismo personaje

deslumbrado con el resplandor de sus glorias: trocados sus sentimientos de moderación en los de una insufrible altanería; hollando las santas leyes que juró respetar, y que poco antes fueron su apoyo: atacando con la misma furia con que pudiera a una fortaleza enemiga en la campaña, el santuario mismo donde se dictaron: hundiendo a sus legisladores ve- nerables, en los calabozos inmundos, a pesar de la inviolabilidad de sus personas por sus opiniones y de su inocencia, y confundiéndolos con los verdaderos criminales: subiendo al solio por medios bajos y degradantes, que solo podía excogitar una ambición ilimitada: derrocado en breves días de aquel elevado puesto: confinado de su patria más allá de los mares, y a remotas regiones: proscrito por los legisladores de ella, como enemigo público: inmolado, en fin en Padilla, y dado en espectáculo a los aspirantes temerarios. iOjalá y que hubiéramos podido (aunque eficazmente lo intentamos) haberlo distraído de que llegase a un fin tan trágico, para no amargar en ese momento la memoria de sus triunfos! Iturbide tiene derecho a nuestra eterna gratitud por lo bueno que hizo, no por lo mucho malo: su ambición nos precipitó en un abismo de males, de que sepa Dios cómo saldremos (Bustamante, 1845: 337).

Bustamante aseguraba que era preciso repasar los hechos acaecidos desde la caída de Iturbide para evitar volver a ese aborrecible sistema político, pero temía la intervención de una "odiosa potencia extranjera” que intentara imponer a un príncipe en el trono que había quedado vacante. A su decir, el problema del libertador había sido ignorar la voluntad de la nación soberana, que fue coartada por el Plan de Iguala y el Tratado de Córdoba. Ambos planes eran, de acuerdo con Bustamante, "el manantial de los grandes males" que se habían cernido sobre México y eran la base para que Europa pretendiera subyugar a la nación si ésta seguía enfrascada en las luchas de facciones que no habían cesado desde la proclamación de independencia (Bustamante, 1845: 340). En 1827, cuando Bustamante terminó su obra, se habían dado a conocer algunos planes de reconquista militar por parte de España, lo que llevó a que creciera la desconfianza contra los partidarios de la monarquía. En enero de ese año, en México se descubrió una conspiración encabezada por el padre Joaquín Arenas, que desembocó en el encarcelamiento de varios generales y llevó a la convicción de que la antigua 
metrópoli tenía intenciones de imponer un gobierno en el país, de aquí la mención de Bustamante sobre los grandes males que acosaban a la república en esos primeros tiempos de gobierno federal. $Y$ en ese tenor, Iturbide seguía siendo el emblema de los monárquicos que amenazaban la libertad recién conquistada.

En 1831 el yucateco Lorenzo de Zavala publicó su Ensayo histórico de las revoluciones de México, desde 1808 hasta 1830, cuyo objetivo era "dar a conocer el carácter, costumbres y diferentes situaciones de aquel pueblo" (Zavala, 1831: 9). En el prólogo, Zavala afirmó que se proponía desmentir los hechos "falsos, absurdos y ridículos" de los que estaba Ileno el Cuadro histórico de Bustamante (Zavala, 1831: 2). Consideró que para dar a los escritos históricos "el crédito suficiente para formar un juicio recto" era necesaria la imparcialidad, y se propuso a lo largo de toda su obra no formular cargos contra los personajes que presentaría en su relato, sino sólo mostrar cómo habían actuado en las circunstancias que enfrentaron (Lozano, 1997: 225). A decir de Teresa Lozano (1997) Zavala fue "uno de los más auténticos liberales mexicanos de la primera mitad del siglo XIX" y en su obra manifestó las principales características del pensamiento liberal de esa época: su rechazo a la participación de la Iglesia en los asuntos de gobierno, su crítica al despotismo español, su optimismo sobre el brillante futuro de las repúblicas hispanoamericanas y su admiración por el sistema político estadounidenses (Lozano, 1997: 236).

En su obra, Zavala introdujo su retrato de Iturbide con una reflexión sobre las anomalías de las revoluciones de los pueblos, ya que "hombres que habían seguido un partido, que habían peleado por ciertos principios; que habían hecho sacrificios por sostener algunas opiniones o personas, repentinamente cambiaban, y una marcha enteramente contraria sería desde entonces la base de su conducta futura" (Zavala, 1831: 110). Para él, nadie hubiera podido pensar que el oficial mexicano que más crueldades había cometido en contra de sus conciuda- danos para sostener "la esclavitud de su patria", fuera el destinado a encabezar el movimiento que destruyó el poder español en estas tierras. De acuerdo con Zavala, Iturbide estaba dotado de cualidades brillantes, entre las que destacaban su valor y actividad poco comunes. Era fuerte y vigoroso y tenía un carácter altivo y dominante, que le había causado problemas con la autoridad por su natural rechazo a obedecer órdenes. Indudablemente, el vallisoletano "tenía un alma superior y su ambición estaba apoyada en aquella noble resolución que desprecia los peligros y que no se detiene por obstáculos de ninguna especie". Era consciente de su superioridad y por ello no vaciló en ponerse a la cabeza del proyecto que logró la independencia (Zavala, 1831: 111-112). Desde la perspectiva de don Lorenzo, el Plan de Iguala era "una obra maestra de política y de saber" cuyos principios de independencia, unión y religión conciliaban todos los intereses. Con ese Plan, "todos los hijos del país se unían en el principio de nacionalidad; cada uno reservaba para después sus pretensiones diferentes" (Zavala, 1831: 112-113).

Sobre el encuentro de Iturbide con Vicente Guerrero, Zavala enfatizó la desconfianza que aquél inspiraba en el caudillo del sur, que había sufrido su crueldad. No obstante, "Iturbide, aunque sanguinario, inspiraba confianza por el honor mismo que él ponía en todas sus cosas. No se le creía capaz de una felonía, que hubiera manchado su reputación de valor y de nobleza de proceder" (Zavala, 1831: 116). Una vez que las tropas del Ejército Trigarante tomaron la ciudad de México, comenzaron a escucharse voces que aclamaban a Iturbide como emperador. Zavala asegura que si esa era la pretensión de Agustín, debió preparar los medios para lograrlo en ese momento en que gozaba del apoyo casi total de los mexicanos, pero en cambio acabó por no hacer "ninguna cosa útil a su patria, ni menos satisfacer su ambición, que no podía ocultar a pesar de sus fingidas demostraciones de desprendimiento que servían más para descubrir que para ocultar sus intenciones". Como había costado muy poco el triunfo sobre los enemigos 
de su patria y había conquistado con facilidad a la opinión pública, creyó que podría "disponer de ella como se usa de un capital para compras y ventas". Eso le hizo pensar que nadie se atrevería a disputarle su autoridad ni sus derechos y su mayor desgracia, de acuerdo con Zavala, fue tratar de emular "al hombre extraordinario que acababa de desaparecer en Santa Elena". Esas "ridículas pretensiones" serían la causa de su perdición (Zavala, 1831: 127). Zavala criticó abiertamente las ambiciones de Iturbide, que lo llevaron a aceptar la corona de un gobierno monárquico cuando no tenía la energía ni la fuerza para llevar a buen fin su proyecto. A decir de don Lorenzo, el emperador, vistas las difíciles circunstancias que enfrentaba debió renunciar al mando y retirarse a la vida privada. Pero "le faltaba resolución aun para ese acto de desprendimiento: quería ser llamado el Washington mexicano sin las grandes virtudes de ese padre de la independencia americana, y aspiraba a imitar a Napoleón sin siquiera un rasgo del carácter del héroe" (Zavala, 1831: 139-140). En el mismo tono que Bustamante, criticó que Iturbide hubiera traicionado los ideales de independencia al aceptar ser cabeza de una monarquía, pero también lo acusó por su indecisión. De acuerdo con Zavala, "muchos fueron los errores de Iturbide y las causas de su catástrofe. Pero la primera y principal falta fue el estado de indecisión en que permanecía en las más críticas circunstancias". De la noticia de su muerte, lamentó la suerte corrida por Iturbide, y criticó "la exultación y gozo de los indignos mexicanos que aborrecían en Iturbide al libertador de su patria”. También criticó que los integrantes del Congreso no se hubieran expresado contra un acontecimiento que merecía la condena abierta a quienes habían dado la orden de fusilar al exemperador (Zavala, 1831: 294).

La imagen que sobre Agustín I nos presenta el historiador yucateco es, tal como lo pretendía, mucho más equilibrada que la de Rocafuerte o Bustamante. Reconoce sus cualidades y también evidencia sus defectos. Y no obstante no comulgar con su proyecto monárquico y ser un abierto defensor del republicanismo, reconoce los méritos de Iturbide al haber logrado la Independencia. Su triste final es motivo de reflexión sobre la posibilidad de que las disputas y las divisiones se ahonden en México a pesar del triunfo del proyecto liberal. Zavala ocupó varios cargos políticos, fue gobernador del Estado de México, acompañó a Vicente Guerrero en su efímero gobierno y nunca dejó de reconocer las bondades del Plan de Iguala, por su propuesta incluyente. Así lo muestra el hecho de que se opusiera al decreto de expulsión de españoles emitido en 1829 porque traicionaba las promesas de Iguala y los pactos del Tratado de Córdoba (Lozano, 1997). En sus últimos años apoyó la independencia de Texas, provincia en la que murió, lo que nos habla de su decepción frente a la anarquía y las disputas políticas que caracterizaron el México de entonces.

En noviembre de 1833, durante la primera presidencia de Antonio López de Santa Anna, se dispuso que los restos de emperador, que habían sido enterrados en Padilla, fueran trasladados a la Ciudad de México y depositados en la urna dedicada a los primeros héroes de la independencia. El decreto de la Secretaría de Guerra y Marina, del 3 de noviembre de ese año, asentó que la nación mexicana "reconocía como a uno de los principales autores de su independencia a D. Agustín de Iturbide por haberla proclamado en Iguala y conquistándola con prudencia y valor" (Tornel y Mendívil, 1833). Pero fue hasta 1838, bajo el gobierno de Anastasio Bustamante durante el periodo centralista, que finalmente se cumplió el cometido de trasladar los restos y hacer honras fúnebres al consumador de la independencia. A decir de José Ramón Pacheco, el "hombre de su siglo, el hijo más caro de la patria, el padre de los mexicanos, el que tenía por familia a millares de hombres", que había muerto como criminal sin honores, iba a ser reivindicado porque había llegado el día en que la patria "libre de los que la engañaron y dominaron a su turno, se abandonase a su llanto e hiciese los honores debidos a su hijo, a su padre, a su libertador" (Pacheco, 1849: 6). La nación finalmente reconocía los méritos de Iturbide 
y el 26 de octubre de 1838, 17 años después de la consumación de la independencia, "el día de la reparación", sus restos fueron depositados en la Catedral Metropolitana, en la capilla de San Felipe de Jesús (Pacheco, 1849: 26-33). De acuerdo con este relato, sus exequias estuvieron pletóricas de toda clase de gente que buscaba rendir honores a quien tan injustamente había perdido la vida por un infame decreto del Congreso, lo que demostraba que seguía vivo en la memoria de los mexicanos (Pacheco, 1849: 42). Si los restos de Iturbide no fueron depositados en el sepulcro que contenía las cenizas de Hidalgo y sus compañeros, fue porque Bustamante y los iturbidistas consideraron que sería una profanación que se mezclaran unos con otros. Así, "quedaron tan separados en muerte como lo habían estado en vida” (Alamán, 1852, t. v: 803).

\section{La visión conservadora sobre el "héroe de Iguala"}

Si cansados de desórdenes y de una lucha sangrienta, nos conformamos con nuestro envilecimiento y preparamos la pérdida de nuestra nacionalidad, no habrá un Iturbide que repare nuestros extravíos y despierte en nosotros el valor y las virtudes

que son propias de nuestra raza.

Su muerte es precursora de todas las calamidades que va a sufrir esta nación [...]

LUIS G. Cuevas (1851: 315)

En los años del centralismo comenzó a perfilarse un proyecto monárquico de la mano de José María Gutiérrez de Estrada, quien en una carta dirigida al presidente Bustamante afirmó que en México todos los sistemas políticos ensayados desde la Independencia habían fracasado, y que no había hombres capaces de hacerse cargo del gobierno. Más adelante, publicó en el Diario del Gobierno varios textos en los que propuso abiertamente que, dado el fracaso del sistema republicano, como lo probaban los múltiples conflictos vividos en el país desde su inde- pendencia, debía ensayarse un gobierno monárquico "en la persona de un príncipe extranjero” (Villavicencio, 2015: 94-96). El escándalo que se suscitó por las propuestas de Gutiérrez de Estrada causó el exilio del personaje, que no volvió al país. Pero su propuesta fue la punta de lanza que acabaría impulsando el proyecto conservador de la década de los años sesenta.

Fue precisamente a fines de la década de los cuarenta cuando Lucas Alamán definió cuáles eran los objetivos del conservadurismo, opción política que se identificó abiertamente con el héroe de Iguala. En su Historia de Méjico, que comenzó a publicar a fines de esa década, Alamán presentó una imagen de Iturbide muy distinta a la que habían plasmado Bustamante, Zavala y, por supuesto, Rocafuerte. En el prólogo de su Historia aseguró que, dado que era testigo de lo ocurrido desde la independencia, y en vista de tantos errores de los que habían escrito sobre esos acontecimientos, llevados por la ignorancia, la mala fe o el espíritu de partido, él se sentía obligado a narrar cómo habían sucedido los hechos que llevaron a la independencia de México (Alamán, 1852: t. I, III). A su decir, en su obra no presentaba "colosos, como algún otro escritor lo ha hecho en estos días, porque no he encontrado más que hombres de estatura ordinaria, ni he atribuido a grandes y profundas miras, sucesos que se explican naturalmente por otros contemporáneos"; su intención era presentar "las cosas tal como fueron" (Alamán, 1852: t. v: x). En su retrato de Iturbide, habló de sus destacadas acciones como soldado realista, en las que se condujo "con la serenidad y bizarría del más aguerrido veterano" (Alamán, 1852, t. v: 54). "Severo en demasía con los insurgentes, deslució sus triunfos con mil actos de crueldad y con el ansia de enriquecer por todo género de medios", por lo que fue suspendido (Alamán, 1852, t. v: 55). De esa manera, Iturbide "en la flor de la edad, de aventajada presencia, modales cultos y agradables, hablar grato e insinuante, bien recibido en la sociedad, se entregó sin templanza a las disipaciones de la capital, que acabaron por causar graves 
disensiones en el interior de su familia, y le dieron ocasión de ejercer su carácter imperioso" (Alamán, 1852, t. v: 56). A decir de don Lucas, si bien Iturbide había hecho la guerra a los insurgentes de manera encarnizada, "no por eso era menos inclinado a la independencia, como todos los americanos", y a sus amigos les había expresado que el inútil derramamiento de sangre podía terminar si aquéllos se pusieran de acuerdo "con las tropas mexicanas que militaban bajo las banderas reales" (Alamán, 1852, t. v: 56). ${ }^{5}$ Sin embargo, dado que los insurgentes eran un "completo desorden" y se habían propuesto un "sistema atroz" era necesario acabar con ellos antes de emprender otras acciones a favor de la libertad (Alamán, 1852, t. v: 57). Cuando finalmente se prestó el momento para encabezar la rebelión, Iturbide "se arrojó pues a la empresa, contando sólo con el influjo que el mando debía darle; con su arte de ganar a la tropa, y sobre todo con el estado de la opinión (...). Conoció las circunstancias, supo sacar partido de ellas, y en esto consistió todo el resultado que obtuvo" (Alamán, 1852, t. v: 73).

El mayor mérito de Iturbide, de acuerdo con Alamán, fue el Plan de Iguala con sus tres garantías. Su proyecto monárquico buscó dar a la nueva nación "un gobierno vigoroso, único capaz de salvarla en el contraste de tan encontrados intereses, y el solo que podía reunirla alrededor de una bandera en los momentos en que la unidad era más necesaria" (Alamán, 1852, t. v: 113). Don Lucas equiparó a Iturbide con Simón Bolívar, "los dos hombres superiores que la América española ha producido en la serie de tantas revoluciones" (Alamán, 1852, t. v: 115). Del gobierno imperial y la caída de Iturbide, Alamán afirma que su ruina fue consecuencia de la escasez de recursos, de los malos consejos de sus allegados y, sobre todo, del disgusto que había causado en la sociedad su elevación al trono y el ensalzamiento de

5 Nótese que, para Lucas Alamán, todos los americanos querían la independencia y los soldados realistas eran mexicanos. Aquí se enfatiza el carácter de guerra civil de la lucha por la independencia, ya que eran americanos y mexicanos quienes peleaban en los dos bandos. (Las cursivas son mías.) su familia (Alamán, 1852, t. v: 756). Sobre la muerte de Iturbide y el destino de sus restos, Alamán dijo:

Este ha sido el único tributo de reconocimiento pagado a la memoria de Iturbide. Cuando por efecto del transcurso del tiempo, olvidados todos los extravíos del hombre, sólo quedan presentes los beneficios que de él se han recibido, el fundador de la independencia mexicana parece que hubiera debido obtener otras pruebas de gratitud de aquella nación que él elevó a la clase de tal; pero el empeño que ha habido en despojarlo de este mérito ha sido la causa de que se la haya visto con tanta indiferencia. [Es sorprendente] que en toda la república mexicana no se haya erigido ninguna [estatua] a Iturbide: una se ha levantado a Hidalgo en Toluca; dos van a dedicársele en Guanajuato; varias ciudades han tomado los nombres de los promovedores de la revolución del año 1810 [...] el nombre de Iturbide no lo lleva población alguna importante y apenas lo tiene alguna calle de algún pueblo pequeño, ni hay más inscripción en su honor que la que está sobre su modesto sepulcro (Alamán, 1852, t. v: 803-804).

Esta imagen no estuvo exenta de críticas, pero sin duda prevaleció en Alamán la admiración por la forma en que Iturbide consumó la independencia. Destacó las garantías del Plan de Iguala por su carácter conciliador que aseguraban un gran porvenir para la patria al desatar sin romper los lazos que unían el pasado con el presente. Si criticó el intento de formar un imperio sin legitimidad y sin cimientos, justificó a Iturbide al afirmar que era fruto de la inexperiencia y el desvío provocado por la adulación de sus simpatizantes. La caída del primer imperio había sido el germen de la senda fatal por donde el país caminaba a mediados de la centuria. Desde el punto de vista del guanajuatense, que expresó en varios artículos publicados en el periódico El Tiempo, la unidad social, política y religiosa de México aconsejaba la forma monárquica de gobierno. En cambio, se había promulgado "la absurda Constitución de 1824", lo que originó la desorgani- 
zación de la hacienda, la destrucción de la administración, la dilapidación de los caudales, la debilidad de la nación y las revueltas continuas que habían acabado con la libertad civil (Alamán, 1998: 73). El pesimismo de Alamán en sus últimos años es entendible si se toma en cuenta que fue testigo de todos los problemas enfrentados por México en las casi tres décadas transcurridas desde la consumación de la independencia. Su muerte, acaecida en 1853, lo salvó de ver al país sumido en la discordia y la anarquía provocadas por el enfrentamiento entre dos proyectos de nación que se manifestó abiertamente a partir de la Reforma.

La visión favorable al libertador, sostenida por la opinión conservadora en los años de la lucha con los liberales, también se plasmó en una pequeña biografía que escribió José Joaquín Pesado para el Diccionario Universal de Historia y Geografía y que se publicó como apéndice al tomo IV en 1856. En ese trabajo, Pesado exaltó como el verdadero libertador de México a Iturbide y tal como la había hecho Lucas Alamán, juzgó con severidad a Miguel Hidalgo; consideró la primera etapa del movimiento de independencia como retardadora, más que impulsora de la emancipación nacional (Roa Bárcena, 1962: 86-87). De acuerdo con José María Roa Bárcena, Pesado no era adicto al militarismo ni tenía fe en la posibilidad de establecer una monarquía con la ayuda europea, pero sí estaba dispuesto a participar en la defensa de la Iglesia y de la religión. Con ese fin dirigió el semanario La Cruz entre enero de 1856 y julio de 1858, y en sus páginas escribió sobre diversos temas y se convirtió en uno de los más reconocidos polemistas de su tiempo. Entre sus artículos destacan los que dedicó a señalar las "contradicciones" del liberalismo; atacó la desamortización de bienes eclesiásticos; se pronunció contra la supresión de órdenes monásticas, la tolerancia de cultos y la Constitución de 1857. Para José Joaquín, un "gobierno justo y templado" debía ser aquel que uniera a los ciudadanos con el lazo común de la fe. En lugar de separarse de la Iglesia, debía "buscar en ella el mejor apoyo a las instituciones políticas, el título más seguro de su poder, y la garantía más preciosa de obediencia de sus súbditos" (Gómez-Aguado, 2002: 47-48).

En cuanto a la biografía de Iturbide, presentó una imagen sumamente favorable del libertador. Es claro que utilizó la Historia de Méjico de Alamán, ya que en algunas partes copia casi textualmente partes de la obra, pero lejos de las pretensiones del guanajuatense con respecto a mostrar al hombre de carne y hueso, con todas sus contradicciones, Pesado justificó los actos controvertidos del consumador de la Independencia y exaltó sus acciones heroicas. De él dijo que "eran seguros sus planes, acertadas sus disposiciones e infatigable su actividad" (Pesado, 1872: 8). Sobre la guerra que Iturbide hizo a los primeros insurgentes, Pesado lo defendió de las acusaciones de crueldad por los fusilamientos que ordenó, cuando las tropas de Hidalgo habían hecho lo mismo con los prisioneros enemigos e incluso con los españoles pacíficos. Decía que "declamar contra las ejecuciones que por justa represalia hacían las tropas realistas, no era escribir la historia con imparcialidad". Iturbide "conocía que la guerra debía hacerse sin tregua y sin intermisión” (Pesado, 1872: 8-9). Cuando Agustín se hizo cargo de las provincias de Guanajuato y Valladolid, el virrey recibió continuas quejas por sus abusos, pero Pesado lo justificó diciendo que

\begin{abstract}
si bien algún exceso de severidad y algunas medidas violentas, propias en los hombres nuevos, constituidos en autoridad, y favorecidos por la victoria, concitaron contra él la animadversión de casas y personas influyentes de Guanajuato y Querétaro [...] Iturbide se quejó de que la calumnia obraba en ellas (Pesado, 1872: 12-13).
\end{abstract}

Era natural, afirma Pesado, que a los hechos verdaderos se añadieran otros falsos y que hubiera exageración en esos testimonios. De cualquier modo, fue retirado del mando y entonces "dio pábulo a los deseos de independencia” (Pesado, 1872: 12-13).

Por lo que toca al Plan de Iguala, Pesado afirmó que Iturbide, 
aleccionado con los desaciertos de Hidalgo, concibió un plan enteramente diverso, que él mismo redactó con admirable sagacidad. Fijó en él tres bases cardinales y fueron: la religión, la unión entre españoles y americanos y la independencia. Con la primera imprimía un carácter venerable a su plan; cuanto hay grande, útil y sólido en la América española, se debe al catolicismo, que fue el que civilizó a sus naturales y formó la sociedad actual: con la segunda organizaba e infundía nueva vida al orden civil, peligrosamente herido con los planes de odio y exterminio de los primeros insurgentes; y con el tercero daba origen a un nuevo sistema político, indispensable en aquellas circunstancias, en que el orden antiguo perecía sin remedio, por el desconcierto en que acababa de entrar toda la monarquía española (Pesado, 1872: 14-15).

Con la consumación de la Independencia y la entrada del Ejército Trigarante en la ciudad de México terminó la gloria de Iturbide. A decir de Pesado, "el que había combinado una revolución con tanto tino, no fue bastante a crear un gobierno sólido, y menos a superar las dificultades que el partido liberal le sembraba a cada paso" (Pesado, 1872: 39). La instalación del Congreso, formado por hombres poco preparados para ejercer el cargo que detentaban y la proclamación de Iturbide como emperador sí fueron criticados por Pesado, que afirmó que esa corte improvisada en un país sin recursos para sostener ese tren de gastos tenía que tropezar y quedar en ridículo (Pesado, 1872: 4849). Los defectos e inexperiencia de Iturbide contrastaban, de acuerdo con Pesado, con su noble carácter que pudo ayudarlo a servir a su patria si se hubiera abstenido de aceptar la corona imperial. Al querer regir al país con un nombre inútil, se había creado envidias e innumerables dificultades, pero si bien era amigo de la gloria, deseaba sinceramente la felicidad de su patria, apreciaba el mérito ajeno y era desprendido y desinteresado. "Su carácter, inteligencia y prendas personales lo hacían muy superior a sus enemigos" (Pesado, 1872: 52). Sobre la abdicación y la muerte de Iturbide, Pesado concluyó: "así acabó el primer hombre que ha producido México: el que mejor conoció lo que le convenía; y el que si bien cometió graves errores en su gobierno, dio grandes muestras de generosidad y desinterés. Él valía, como ya hemos dicho, más que todos sus enemigos" (Pesado, 1872: 77).

José Joaquín Pesado deja un cuadro muy favorable de Iturbide, a quien pinta con los colores del mártir que dio la vida por la patria. Justifica los yerros del emperador, exalta sus virtudes y, sobre todo, lo presenta como el creador de un proyecto que, si no hubiera fracasado, habría logrado la paz y la prosperidad de la nación mexicana. Esa visión fue compartida por la opinión conservadora que más adelante apoyó la idea de que el único sistema político que podría sacar a México del caos y la anarquía sería un gobierno monárquico que diera continuidad al plan iturbidista. Así, frente al avance del liberalismo encabezado por Benito Juárez, los simpatizantes del imperio creyeron necesario regresar a los postulados del Plan de Iguala, ya que era la propuesta que en su momento había logrado una aceptación generalizada por su tono conciliador, además de que ofrecía el trono a un monarca europeo (Villavicencio, 2015: 296). José Joaquín Pesado no vio cristalizado el proyecto que con seguridad habría apoyado, ya que falleció en 1861, pero muchas de las ideas que él defendió en el periódico La Cruz fueron la base de la propuesta monárquica que se ensayó unos años más adelante.

\section{Epílogo: Iturbide después del triunfo de la República}

El papel más importante en la creación de mitos históricos fue el que se promovió a través de la obra cumbre de la historiografía liberal decimonónica: México a través de los siglos. En ese relato evolutivo sobre el pasado, escrito en la década de los años ochenta, quedaron marcadas con tinta indeleble las características de los personajes históricos que todavía hoy en día forman el imaginario popular sobre los héroes. Después de las polémicas sobre la imagen de Iturbide en 
las primeras décadas de vida independiente, en México a través de los siglos fue descrito como un hombre ambicioso, corrupto y advenedizo, aunque hábil y calculador:

La ferocidad de Iturbide fue verdaderamente espantosa, y le hemos visto desplegarla no solo en los campos de batalla y contra los prisioneros de guerra, sino también contra muchos vecinos pacíficos [...] y esta crueldad que lo distinguió siempre durante sus campañas en las filas realistas, demuestra un carácter sanguinario que, al decir de un escritor contemporáneo de Iturbide, se reveló en éste desde sus más tiernos años [...] Al lado de estos gravísimos defectos, que nunca han podido desvanecer los defensores de Iturbide, adornaban a éste raras prendas y calidades prestigiosas que prepararon fácilmente su rápido encumbramiento. Su valor era impetuoso y estaba con suficiencia demostrado; su arrogante presencia y sus cultas y agradables maneras ejercían inevitable influjo en los que lo trataban (Zárate, 1987, t. vl: 275).

Otro rasgo que caracterizaba a Iturbide, de acuerdo con el autor del relato de la independencia, era su profundo fanatismo, ya que siempre "manifestaba los sentimientos religiosos más exagerados". Tenía una insaciable sed de riquezas y llevaba a cabo los medios más indignos para satisfacerla. A decir de Zárate, en la historia de los pueblos existían anomalías inexplicables a primera vista, como el hecho de que Iturbide,

el implacable defensor de la dominación española, el jefe militar que tantas veces empañó el brillo de su acero con la sangre de sus compatriotas, llegase a ocupar el puesto que el destino debió reservarle a Hidalgo y a Morelos [...] parece, en efecto una irregularidad monstruosa" (Zárate, 1987, t. vi: 276).

Pero todo se explicaba al ver que las acciones de Iturbide fueron fruto de su desmedida ambición. Si a Iturbide le hubiera importado realmente la libertad de la patria, se habría unido a quienes peleaban por ella, pero en cambio, había querido exterminar- los, aprovechar para su beneficio "los elementos morales, poderosísimos, que habían fundado con su sangre y sus sacrificios los defensores de la independencia". Ese era el hombre que "los absolutistas eligieron para ejecutar sus proyectos, enderezados a restablecer el antiguo régimen arbitrario y despótico" (Zárate, 1987, t. vI: 276). La imagen que se nos presenta en México a través de los siglos es la de un hombre cuya ambición lo llevó a traicionar todos los principios. Y si bien Zárate reconoció su genio y sus habilidades para lograr la consumación de la Independencia, no dejó de señalar sus defectos, basado en el relato que hiciera Vicente Rocafuerte casi seis décadas atrás. Eso es una muestra de la fuerza de las imágenes que se plasmaron en los primeros relatos de los sucesos que llevaron a la independencia de México.

En el tomo dedicado al México independiente, Juan de Dios Arias también habló de Iturbide en términos muy críticos, aunque reconoció su valor y sus actos heroicos. En primer lugar, le reprochó haber despreciado a los primeros insurgentes, sin cuyo esfuerzo no habría sido posible la consumación. Lo presentó como un hombre rebasado por los acontecimientos e incapaz de hacer frente a los retos que implicaba el ejercicio de gobierno; así, desde la perspectiva de Arias, de héroe se convirtió en tirano (1987: 50-51). Sobre las opiniones críticas que Iturbide expresó en sus memorias (2007) acerca de los miembros del Congreso, Arias afirmó que sus "resentimientos fueron sin duda el móvil de sus apreciaciones, en las que descendió hasta el inculto lenguaje de un difamador o denunciante vulgar" (Arias, 1987: 55). De la proclamación de Iturbide como emperador, afirmó que

su carácter imponente, altivo y audaz, acostumbrado a no sufrir contradicción y educado en los campos de batalla, bajo la influencia de una política vengativa y sanguinaria y el envanecimiento de su elevación, que tal vez creyó debida a su solo y exclusivo mérito, sin contar los múltiples y poderosos elementos que facilitaron su última empresa, le impidieron seguir 
el venturoso derrotero destinado a los grandes genios, y lo precipitaron en la torcida senda del error y del despotismo (Arias, 1987: 81).

Sobre su caída y su renuncia al trono, Arias concede que Iturbide obró con prudencia y se hizo a un lado para no seguir acrecentando la anarquía que reinaba entonces en el país. Su humillante salida de México marcaba la caída del "intrépido soldado que apenas hacía diez meses lograra ceñir su frente con la diadema de los césares" (Arias, 1987: 92). De acuerdo con la imagen que nos deja Arias, Iturbide era impaciente y fogoso y no toleraba que se le contradijese. Fue benévolo con sus amigos, pero inclemente con sus adversarios, valiente para la guerra, pero sin vigor para contrarrestar el embate de las pasiones políticas. Puede decirse de él que fue hombre de pasiones vulgares, víctima de sus propios defectos. Pero por el hecho de haber logrado la hazaña de Iguala no debía pasar a la historia como un criminal, sino "como una persona ilustre que hizo bien a su patria y a quien sus conciudadanos deben un recuerdo constante de justa gratitud" (Arias, 1987: 111). De esa manera, Juan de Dios Arias presentó un retrato de Iturbide más equilibrado que Zárate, reconoció cualidades y valor en Iturbide, aunque criticó su falta de talento para llevar a buen puerto el gobierno que comenzó con tan buenos augurios y terminó en la tragedia del fusilamiento del emperador.

En contraste, en el relato que hiciera $\mathrm{Ni}$ ceto de Zamacois sobre la consumación de la Independencia en su Historia de Méjico, se basó en la obra de Lucas Alamán para recrear aquellos acontecimientos, por lo que las imágenes de Iturbide son casi iguales a las que plasmó aquél. Pero entre las páginas de su Historia, Zamacois expresó algunas opiniones sobre los sucesos que llevaron a la caída del héroe de Iguala. A su decir, "la grandeza y poder del emperador Iturbide fueron de un instante" (Zamacois, 1888, t. x: 511). Una las consecuencias de su caída fue que la unión de sus enemigos favoreció a los simpatizantes de la insurrección de Miguel Hidalgo, lo que llevó a que trataran de ensalzar los servicios prestados por éste a la causa de la independencia con el fin de menoscabar el papel jugado por Iturbide y, de ese modo, conseguir que la gente le perdiera el afecto que le tenía. Ese fue el origen de que el 27 de septiembre quedara olvidado en las conmemoraciones de la independencia, y en cambio, se celebrara siempre el 16 de septiembre para recordar el grito del cura de Dolores. A pesar de que ambos hechos, a decir de Zamacois, tenían igual derecho a la gratitud nacional, y siempre debieron celebrarse con igual boato, se dejó de celebrar el 27 porque los políticos de entonces "consideraban peligroso que se conservase la memoria del notable servicio hecho a la patria por Iturbide y procuraron evitar toda demostración que pudiera recordarlo al pueblo" (Zamacois, 1888, t. x: 525-526).

De acuerdo con la visión conciliadora que Zamacois trató de plasmar en su Historia de Méjico, en su reflexión sobre el papel que jugaron los dos protagonistas de la independencia expresó su deseo de que ambos fueran reconocidos por sus indudables méritos:

Censúrense, si se quiere, los actos del cura Hidalgo como gobernante y los de Iturbide como emperador; háganse ver enhorabuena los errores en que incurrieron como hombres de gobierno; pero no se vulnere al caudillo de Dolores ni al de Iguala: elógiese el pensamiento de amor a la patria que guio a los dos, al dar el grito de independencia en diversas épocas, y celébrese el día 16 de septiembre de 1810 y el 27 del mismo mes del año 1821, entonando himnos de gratitud a los que proclamaron la emancipación del suelo en que nacieron (Zamacois, 1888, t. x: 527).

Al reflexionar sobre las imágenes de Agustín de Iturbide que hemos revisado en este trabajo, podemos darnos cuenta de lo difícil que es hacer un balance de su figura si nos basamos en lo que sobre él dijeron varios de sus contemporáneos a lo largo de las décadas que siguieron al triunfo de su movimiento. Es un hecho que Iturbide desató pasiones desde que saltó a la fama pública al consumar la Independencia, y que sus ad- 
miradores, tanto como sus malquerientes, se ocuparon de exaltarlo o denostarlo con igual pasión. La herencia de esa historiografía decimonónica que utilizó al libertador a modo de bandera política, tal como hemos visto en los relatos de tendencias conservadoras o liberales sobre la independencia, hizo muy difícil tener una imagen ponderada de sus acciones. El proyecto monárquico que estuvo latente en el país hasta la caída del segundo Imperio representó una amenaza constante para quienes consideraban que el único camino para la nación era la república. En ese sentido, la imagen de Iturbide en la historiografía fue una manifestación más de las luchas de facciones que caracterizaron al siglo XIX. En este 2021, cuando se conmemoran 200 años de los acontecimientos que hemos recordado en estas líneas, quizás no sea una vana ilusión esperar que la figura de Agustín de Iturbide sea analizada con menos pasión y mayor seriedad, que se reconozcan sus indudables méritos y deje de ser un personaje ignorado, denostado o exaltado, como lo ha sido en el tiempo transcurrido desde que el 27 de septiembre de 1821 proclamó la libertad de la patria mexicana.

\section{Fuentes consultadas}

Aguilar Rivera, José Antonio (2012), "Vicente Rocafuerte y la invención de la república hispanoamericana", en Ausentes del universo. Reflexiones sobre el pensamiento público hispanoamericano en la era de la construcción nacional, 18211850, Ciudad de México, FCE/CIDE, pp. 67-101.

Alamán, Lucas (1849-1852), Historia de Méjico desde los primeros movimientos que prepararon su independencia en el año de 1808 hasta la época presente, 5 vols., Ciudad de México, Imprenta de J. M. Lara.

Anna, Timothy E. (1991), El Imperio de Iturbide, Ciudad de México, Alianza Editorial/Conaculta.
Anónimo (1825), Catástrofe de D. Agustín de Iturbide, aclamado emperador de México el 18 de mayo de 1822 o relación exacta de las circunstancias que han acompañado el desembarco y la muerte de este hombre célebre, París, SPI.

Arias, Juan de Dios (1987), México independiente, t. VII, en Vicente Riva Palacio (coord.), México a través de los siglos. Historia general y completa del desenvolvimiento social, político, religioso, militar, artístico, científico y literario de México desde la antigüedad más remota hasta la época actual, Ciudad de México, Cumbre.

Arrom, Silvia Marina (2020), La Güera Rodríguez. Mito y mujer, México, Turner.

Ávila, Alfredo (2010), "Claroscuros de Iturbide", Nexos, núm. 393, Ciudad de México, pp. 21-22.

Ávila, Alfredo (2008), "El gobierno imperial de Agustín de Iturbide", en Will Fowler (coord.), Gobernantes Mexicanos. I: 1821-1910, Ciudad de México, FCE.

Bustamante, Carlos María de (1844-1845), Cuadro histórico de la revolución mexicana, comenzada el 15 de septiembre de 1810 por el ciudadano Miguel Hidalgo y Costilla, cura del pueblo de Dolores en el obispado de Michoacán, t. V, Ciudad de México, Imprenta de Cumplido.

Cuadriello, Jaime (2010), "Interregno II: el exilio de Agustín I", en Bernardo Esquinca Azcárate, Evelyn Useda Miranda y Jenny Jiménez Herrada (coords.), El éxodo mexicano. Los héroes en la mira del arte, Ciudad de México, UNAM/Fomento Cultural Banamex, pp. 144-189.

Cuevas, Luis G. (1851), Porvenir de México o juicio sobre su estado político en 1821 y 1851, Ciudad de México, Imprenta de Cumplido.

Del Arenal Fenochio, Jaime (2010), Unión, independencia, Constitución. Nuevas reflexiones en trono a Un modo de ser libres, Ciudad de México, INEHRM. 
Del Arenal Fenochio, Jaime (2002a), Agustín de Iturbide, México, Editorial Planeta Mexicana.

Del Arenal Fenochio, Jaime (2002b), Un modo de ser libres. Independencia y Constitución en México (1816-1822), Zamora, El Colegio de Michoacán.

Díaz Noriega, José Manuel (1860), Funestos recuerdos del libertador de México. Exhumación y autenticidad de sus respetables restos, conducidos desde Padilla, y depositados actualmente en la Santa Iglesia Catedral, que al señor D. José Ramón Malo, dedica el general José María Díaz Noriega, oficial mayor jubilado del Ministerio de Guerra y Marina, secretario honorario de Estado y del Despacho, Ciudad de México, Imprenta de J. M. Lara.

Espinosa Aguirre, Joaquín E. (2020), "Los libros sobre el libertador. Doscientos años de historiografía biográfica sobre Agustín de Iturbide", en Boletín del Archivo General de la Nación, núm. 6, Ciudad de México, AGN, pp. 125-158.

Estrada Michel, Rafael (2021), "La idea de reino, el programa constitucional pluralista y la figura histórica de Agustín de Iturbide", en José Luis Soberanes Fernández y Ana Carolina Ibarra (coords.), El bicentenario de la consumación de la independencia y la conformación del primer constituyente mexicano, Ciudad de México, UNAM-Instituto de Investigaciones Jurídicas-Instituto de Investigaciones Históricas, pp. 303-320.

Fernández de Lizardi, José Joaquín (2016), El unipersonal de don Agustín de Iturbide, emperador que fue de México, Madrid, Fundación Biblioteca Virtual Miguel de Cervantes, <https://bit.ly/3y9jxSG>, 5 de junio de 2021.

Frasquet, Ivana (2007), "La 'otra' Independencia de México: el primer imperio mexicano. Claves para la reflexión histórica", Revista Complutense de Historia de América, vol. 33, Madrid, Universidad Complutense de Madrid, pp. 35-54.
Florescano, Enrique (2002), Historia de las historias de la nación mexicana, Ciudad de México, Taurus/Pasado y Presente.

Gómez-Aguado de Alba, Guadalupe (2012), "De héroes y antihéroes. El siglo XIX mexicano", en José Luis Palacio Prieto (coord.), 90 años de cultura en el Centro de Enseñanza para Extranjeros, Ciudad de México, UNAM-Centro de Enseñanza para Extranjeros, pp. 59-86.

Gómez-Aguado de Alba, Guadalupe (2002), "Un proyecto de nación clerical. Una lectura de La Cruz. Periódico exclusivamente religioso", tesis de maestría, Instituto de Investigaciones Dr. José Ma. Luis Mora, Ciudad de México.

Iturbide, Agustín de (2007), Memorias escritas desde Liorna, Ciudad de México, UNAM (Colección Pequeños Grandes Ensayos).

Junco, Alfonso (1971), Insurgentes y Liberales ante Iturbide, México, Jus (Colección México Heroico 108).

Lozano Armendares, Teresa (1997), "Lorenzo de Zavala", en Rosa Camelo y Juan Antonio Ortega y Medina (coords.), Virginia Guedea (coord. de tomo), Historiografía Mexicana. El surgimiento de la historiografía nacional, vol. III, Ciudad de México, UNAM-Instituto de Investigaciones Históricas, pp. 213-240.

Moreno, Antonio de P. (1896), Iturbide. Drama histórico en dos partes, Ciudad de México, Tipografía de El Tiempo.

Pacheco, José Ramón (1849), Descripción de la solemnidad fúnebre con que se honraron las cenizas del héroe de Iguala Don Agustín de Iturbide en octubre de 1833, Ciudad de México, Imprenta de I. Cumplido.

Payno, Manuel (1843), Bosquejo biográfico de los generales Iturbide y Terán, México, Imprenta de Ignacio Cumplido.

Pérez Vejo, Tomás (2010), Elegía criolla. Una reinterpretación de las guerras de independencia hispanoamericanas, México, Tusquets/Centenarios. 
Pesado, José Joaquín (1872), El libertador de México D. Agustín de Iturbide, Ciudad de México, Imprenta a cargo de M. Roselló.

Riva Palacio, Vicente (1910), "El libertador de México", en Victoriano Agüeros (ed.), Episodios históricos de la guerra de Independencia relatados por Lucas Alamán, et. al., t. I, Ciudad de México, Imprenta de El Tiempo de Victoriano Agüeros, pp. 309-317.

Roa Bárcena, José María (1962), Biografía de D. José Joaquín Pesado, Ciudad de México, JUS (Colección México Heroico).

Robertson, William Spence (2012), Iturbide de México, Ciudad de México, Fondo de Cultura Económica.

Rocafuerte, Vicente (1822), Bosquejo ligerísimo de la Revolución de México desde el grito de lguala hasta la proclamación imperial de Iturbide por un verdadero americano, Filadelfia, Imprenta de Teracrouef y Naroajeh.

Rodríguez O., Jaime E. (1997), "Vicente Rocafuerte", en Rosa Camelo y Juan Antonio Ortega y Medina (coords.), Virginia Guedea (coord. de tomo), Historiografía Mexicana. El surgimiento de la historiografía nacional, vol. III, Ciudad de México, UNAM-Instituto de Investigaciones Históricas, pp. 169-181.

Tenorio Trillo, Mauricio (2009), Historia y celebración. México en sus centenarios, Ciudad de México, Tusquets/Centenarios.

Tornel y Mendívil, José María (1833), Decreto, Ciudad de México, Secretaría de Guerra y Marina.

Torre Rendón, Judith de la (2011), "Niceto de Zamacois", en Rosa Camelo y Juan Antonio Ortega y Medina (coords.), Antonia Pi-Suñer Llorens (coord. de tomo), Historiografía Mexicana. En busca de un discurso integrador de la nación 1848-1884, vol. IV, Ciudad de México, UNAM-Instituto de Investigaciones Históricas, pp. 549-572.
Valle, Ramón (1885), Bolívar e Iturbide en el centenario de ambos héroes, México, Imprenta de Gonzalo A. Esteva.

Villavicencio Navarro, Víctor Alberto (2015), "El camino del monarquismo mexicano decimonónico: momentos, proyectos y personajes", tesis doctoral, Universidad Nacional Autónoma de México, Ciudad de México.

Zamacois, Niceto de (1888), Historia general de Méjico desde sus tiempos más remotos hasta nuestros días. Ciudad de México, Barcelona, Juan de la Fuente Parrés.

Zárate Toscano, Verónica (1994), “Agustín de Iturbide: entre la memoria y el olvido", Secuencia. Revista de historia y ciencias sociales, núm. 28, Ciudad de México, Instituto de Investigaciones Dr. José María Luis Mora, pp. 5-28.

Zárate, Julio (1987), La guerra de Independencia, t. VI, en Vicente Riva Palacio (coord.), México a través de los siglos. Historia general y completa del desenvolvimiento social, político, religioso, militar, artístico, científico y literario de México desde la antigüedad más remota hasta la época actual, Ciudad de México, Cumbre.

Zavala, Lorenzo de (1831-1832), Ensayo histórico de las revoluciones de Mégico, desde 1808 hasta 1830, 2 vols., París, Imprenta de P. Dupont y G. Laguioni.

Enviado: 2 de agosto de 2021. Reenviado: 4 de agosto de 2021. Aceptado: 10 de agosto de 2021. 


\section{Guadalupe Cecilia Gómez-Aguado de Alba}

Es doctora en Historia por la Facultad de Filosofía y Letras de la UNAM. Actualmente es profesora-investigadora de tiempo completo en el Centro de Enseñanza para Extranjeros de la UNAM. Es Candidata a investigadora por el Sistema Nacional de Investigadores. Entre sus líneas de investigación se encuentran: secularización en el siglo XIX, conservadurismo mexicano, la imagen de la conquista en el siglo XIX y mujeres en el siglo XIX. Entre sus más recientes publicaciones destacan, como autora: "Hernán Cortés y su relación epistolar con Carlos V: el 'fiel vasallo" al servicio de Su Majestad'," en Araucaria. Revista Iberoamericana de Filosofía, Política, Humanidades y Relaciones Internacionales, 23 (47), Sevilla, Editorial Universidad de Sevilla, pp. 69-90 (2021); "Secularización y estrategias pastorales en el arzobispado de México: la Iglesia católica en busca de nuevos caminos", en David Carbajal López (coord.), Proyectos episcopales y secularización en México, siglo XIX, Lagos de Moreno, Universidad de Guadalajara/Centro Universitario de los Lagos, pp. 85-120 (2020) y "La conquista como admirable epopeya o una visión sobre el mestizaje en el México porfiriano", en Alejandro Salafranca Vázquez (coord.), 1521. La conquista de México en el arte, Ciudad de México, UNAM-Secretaría General-Centro de Enseñanza para Extranjeros/El Equilibrista, pp. 127-141 (2020). 